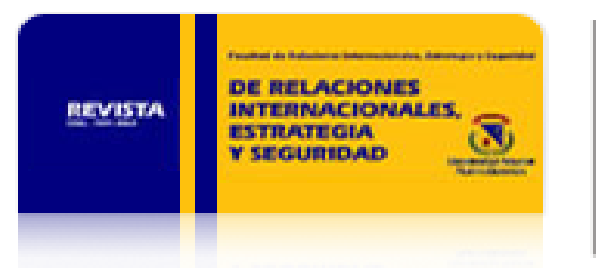

Revista de Relaciones Internacionales, Estrategia y Seguridad

ISSN: 1909-3063

cinuv.relinternal@unimilitar.edu.co

Universidad Militar Nueva Granada

Colombia

Ripoll, Alejandra

Colombia: Semillero para la trata de personas

Revista de Relaciones Internacionales, Estrategia y Seguridad, vol. 3, núm. 1, enero-junio, 2008, pp.

175-174

Universidad Militar Nueva Granada

Bogotá, Colombia

Disponible en: http://www.redalyc.org/articulo.oa?id=92730107

- Cómo citar el artículo

- Número completo

- Más información del artículo

- Página de la revista en redalyc.org

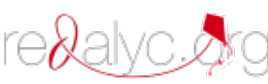

Sistema de Información Científica

Red de Revistas Científicas de América Latina, el Caribe, España y Portugal

Proyecto académico sin fines de lucro, desarrollado bajo la iniciativa de acceso abierto 
rev.relac.int.estrateg.segur.3(1): 175-174,2008

\title{
COLOMBIA: SEMILLERO PARA LA TRATA DE PERSONAS*
}

\author{
Alejandra Ripoll**
}

\section{RESUMEN}

La trata de personas es una violación a los derechos humanos que requiere una especial atención por parte del Estado. Colombia ha mostrado voluntad para combatir eficazmente el delito al suscribir tratados internacionales, promulgar y sancionar leyes nacionales; sin embargo, estas medidas son insuficientes.

Sólo con unas reformas socioeconómicas justas puede garantizar a la mayoría de la población un desarrollo sostenible que disminuya su vulnerabilidad.

Otra tarea de vital importancia para la erradicación del delito de trata de personas en el contexto colombiano, es

* Este artículo forma parte del trabajo de grado que elaboré para obtener mi título de maestría. El documento completo reposa en la biblioteca general de Pontificia Universidad Javeriana Agradezco la colaboración en la corrección del texto a Andrés Quintero y Arturo Cancino.

** Magistra en Relaciones Internacionales, Pontificia Universidad Javeriana, profesora y editora de la Revista de la Facultad de Relaciones Internacionales, Estrategia y Seguridad de la Universidad Militar Nueva Granada. Profesora de la Facultad de Ciencia Política y Gobierno y de Relaciones Internacionales de la Universidad del Rosario. Profesora de la Facultad de Ciencia Política de la Pontificia Universidad Javeriana. aripoll@javeriana.edu.co 
ajustar el sistema de justicia. En la mayoría de los casos los tratantes no son descubiertos, lo que dificulta el sometimiento de éstos a la ley.

Entonces, los hacedores de política, organizaciones públicas y privadas del ámbito nacional tendrán que asumir nuevas actividades frente a los desafíos que presenta el combate de la trata de personas para el Estado colombiano en correspondencia con una estrategia común que privilegie los derechos humanos.

Palabras Clave: trata de personas, derechos humanos, dignidad, libertad, vulnerabilidad, justicia social.

\section{ABSTRACT}

The trafficking in persons is a violation to human rights that requires special attention by the State. Colombia has shown the will to fight effectively this crime by subscribing international agreements, promulgating and sanctioning national laws. Nevertheless, these measures are insufficient. Only by means of fair social-economic reforms it would be possible to guarantee to the majority of the population a sustainable development that diminishes its vulnerability. Another important task in the Colombian context is to adjust the justice system, for in the majority of cases traffickers are not being caught. Hence, politics makers (politicians) and public/private organizations of the national ambience will have to assume new tasks facing the challenges that trafficking in persons present to the Colombian State in correspondence with a common strategy that privileges human rights.

Key words: trafficking in persons, human rights, dignity, freedom, vulnerability, social justice.

\section{INTRODUCCIÓN}

A través del tiempo, el significado de la frase "Trata de Personas"1 ha sido interpretado de muchas maneras por gobiernos, organizaciones y por la comunidad en general. También, ha sido mal usado en algunas situaciones y en otras, para no decir las más, es un concepto desconocido e ignorado.

Para Colombia no es desconocido ni mucho menos ignorado porque ha padecido los embates de la trata de personas desde tiempo atrás. Las primeras referencias se establecen en la época

\footnotetext{
La trata de personas es una violación a los derechos humanos en la que se degrada al ser humano a la condición de cosa. Los fines de la trata de personas son diversos: explotación sexual, trabajos forzosos y la esclavitud, entre otros.
} 
de la Conquista, cuando a los vencedores de las batallas se les entregaba un botín de mujeres, configurándose así el comercio sexual. Luego, en la época de la Colonia, se establecieron en Colombia las primeras zonas de comercio de seres humanos procedentes de África, quienes eran vendidos y comprados como fuerza de trabajo para la agricultura, la minería y el servicio doméstico principalmente.

En el siglo XX, en la década de los setenta empieza el tráfico de mujeres colombianas, enviadas a varios países europeos como España, Italia, Holanda y Alemania para ejercer la prostitución.

Posteriormente, en este siglo no sólo sigue en auge, sino que las cifras han aumentado considerablemente. Igualmente, los objetivos ${ }^{2}$ y fines $^{3}$ han variado, dando como resultado una intensidad sin precedente del delito de trata de personas en Colombia conocido como "la esclavitud del siglo XXI".

Este artículo tiene como objetivo demostrar que a pesar de los ingentes esfuerzos del Estado colombiano por combatir efectivamente la trata de personas; ésta sigue aumentando vertiginosamente por las condiciones socioeconómicas del país. Para lograr este objetivo primero se expondrá cómo ha penetrado el delito, los esfuerzos mancomunados que se han hecho entre los sectores público y privado para combatirlo. En segundo lugar examinar el ámbito legal, para luego concluir que sólo el trabajo conjunto de todos los estamentos, mediante una estrategia consensuada en la que se privilegie los derechos humanos, puede lograr minimizar el impacto de la trata de personas.

\section{CONTEXTO COLOMBIANO}

En el contexto colombiano, la trata de personas es un tema de preocupación que se refleja tanto en la conciencia que se ha tomado frente al problema por parte del Estado, por parte de organizaciones como la Fundación Esperanza y otros estamentos de la sociedad, y en las acciones encaminadas a combatirla. Dentro de las acciones que se han desarrollado están los acuerdos o tratados para atacar internacionalmente las organizaciones criminales transnacionales dedicadas a la trata y al delito mismo. Pese a ello, superar las barreras existentes para combatirlo eficazmente ha sido una tarea difícil con resultados escasos y al contrario, ha crecido y sus métodos cada día son más variados y difíciles de rastrear; es así como en los dos

Las bandas criminales ampliaron el espectro de sus víctimas: no sólo tratan mujeres, sino niños, niñas y hombres.

La explotación además de sexual, se encamina a la laboral, matrimonios de carácter servil, la vinculación a actividades criminales y otros. 
últimos años han aumentado las denuncias ${ }^{4}$ por este delito en el territorio nacional; por eso en algunas regiones se ha intentado trazar políticas que lo prevengan, pero "los colombianos hemos sido golpeados por los embates de la delincuencia organizada" ${ }^{\prime \prime}$, lo que ha llevado a que sea uno de los países más afectados, por el tráfico de personas, pues es país de origen de muchas de las personas tratadas, no sólo para comercio sexual, sino para el tráfico de menores, explotación laboral y otros fines del delito.

Este negocio ilegal tiene mayor ocurrencia en países en vía de desarrollo o subdesarrollados, siendo Colombia uno de los más golpeados ${ }^{6}$ debido a problemas locales como: altas tasas de desempleo, bajos niveles educativos, conflicto armado, ineficiencia del sistema judicial y una economía débil que difícilmente puede involucrarse ventajosamente en la dinámica del Nuevo Orden Mundial para sacar adelante a su población.

Hay que tener en cuenta que "en aquellos países donde el Estado logra proveer plenos servicios de seguridad y justicia para todos, se da por sentada la vigencia de los derechos humanos básicos o de "primera generación"7 (derechos civiles y políticos). Éste no es por supuesto el caso de Colombia, en primer lugar por no tener una cultura de derechos humanos y, en segundo lugar, por las condiciones precarias de muchos sectores de la población, que se ven abocados a prácticas malsanas o a ejercer oficios poco éticos para sobrevivir. Como señala Consuelo Ahumada, "la reducción del papel social del Estado [...] han empeorado las condiciones de vida de la gran mayoría de la población, que no cuenta con los medios para involucrarse en la "racionalidad del mercado" ${ }^{8}$.

Así, la difícil situación socioeconómica de algunas personas las estimula a buscar formas aparentemente fáciles de hacer dinero, lo que en la mayoría de los casos las convierte en víctimas de las bandas criminales organizadas que las someten a todo tipo de labores bajo engaños o

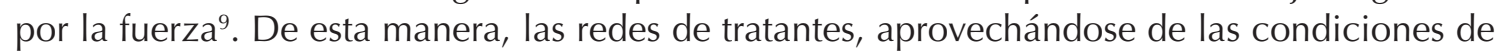

\footnotetext{
Según la Fiscalía General de la Nación y la estadística del DAS el incremento es del 34\% en comparación con años anteriores. Palabras del vicepresidente de Colombia Gustavo Bell, (período 1998-2002), en la conferencia política de alto nivel en Palermo-Italia en el año 2000

6 En el informe anual sobre la trata de personas, 2005 Colombia, el gobierno colombiano calcula que entre 45.000 y 50.000 compatriotas trabajan en el exterior en prostitución. De acuerdo con UNICEF y Human Rights Watch hay entre 6000 y 11000 niños vinculados con grupos armados ilegales en Colombia. Colombia es considerado por las Naciones Unidas como el tercer país exportador de mujeres víctimas de la Trata de Personas, después de Brasil y República Dominicana.

7 PROGRAMA DE LAS NACIONES UNIDAS PARA EL DESARROLLO. Informe Nacional de Desarrollo Humano Colombia - 2003. Cáp.8. p.1.

8 AHUMADA, Consuelo. El Modelo Neoliberal y su impacto en la sociedad colombiana. El Áncora Editores. Bogotá. 1998. p. 246.

9 El caso de Marcela, una estudiante de finanzas de 22 años que decidió irse del país a probar suerte, porque su familia atravesaba una difícil situación. Fue contratada por una agencia de empleos, que tenía contactos en Estados Unidos, Europa y Japón, para consignar dinero en bancos de Europa (trabajo muy fácil). Al llegar a su sitio de destino le quitaron el pasaporte y todos sus documentos, la encerraron bajo llave y sólo salía a hacer las consignaciones. Así, la mantuvieron durante siete meses sin remuneración alguna. Marcela fue utilizada por narcotraficantes para lavar dinero.
} 
pobreza, del conflicto armado interno y de las ansias de un futuro mejor de muchos colombianos y colombianas, los someten a explotación sexual, a trabajos forzados y a otras situaciones similares, como en la época de la esclavitud. Estas razones hacen vulnerable a la población colombiana, presa fácil de los tratantes.

Así, la inestabilidad política y económica aumenta las posibilidades de convertir un país en cantera para la trata de personas. Por lo tanto, facilita la labor de los tratantes que mediante engaño prometen a las víctimas un futuro mejor fuera de las fronteras, ofreciéndoles mejores salarios, mejores condiciones laborales y mejor calidad de vida. Estas condiciones precarias de vida desestabilizan y desplazan a grupos importantes, atraídos por la perspectiva de una vida mejor, desencadenando un gran flujo migratorio de colombianos que muchas veces se convierten en victimas del delito de trata de personas, agravado de hecho por otros factores que identifica Martha Ardila como la globalización, el fenómeno transnacional y las relaciones Norte-Sur, y que en la última década han Ilevado al aumento de la migración nacional en forma significativa.

Así, en esta sociedad globalizada se presenta una paradoja para los migrantes, pues "al mismo tiempo que se da la libre circulación de capitales, ellos viven la creciente restricción de la circulación de personas"10 lo que demanda los servicios de los traficantes por los excesivos controles para migrar legalmente y que posibilitan, aún más, la trata de personas.

A su vez, esto facilita y aumenta la inseguridad de los migrantes exponiéndolos a la dominación y abuso de las organizaciones criminales. En este sentido, las políticas migratorias deben ser diseñadas de manera tal, que garanticen el debido trato a los migrantes y no se conviertan en políticas sancionadoras para las victimas del delito de trata de personas al crear diferencias que categorizan a los seres humanos como de primera y segunda clase, lo que incide para que surjan y aumenten nuevas formas de exclusión social.

Muchos gobiernos todavía responden a la trata a través de políticas restrictivas, lo que hace más vulnerables a los migrantes frente a los traficantes ${ }^{11}$. Este modelo da mayor prioridad a las leyes y a la seguridad de los Estados que a los derechos de las personas traficadas.

En tal caso, la cooperación interestatal es el medio idóneo para reafirmar, favorecer, defender, respaldar o apoyar acciones en contra del delito transnacional en las que se protejan los de-

10 CHIAROTTI, Susana. La Trata de Mujeres: Sus Conexiones y Desconexiones con la Migración y los Derechos Humanos. Naciones Unidas-CEPAL. Serie Población y Desarrollo. \# 39. mayo, 2003. p. 20.

11 BERTONE. Andrea M. Transnational Activism to Combat Trafficking in Persons.College Park Scholars International Studies. P. 16 (traducción libre). 
rechos humanos; por ejemplo, pactar controles fronterizos con los cuales se logre identificar a las víctimas de los tratantes de personas versus simples migraciones ilegales, no violar los derechos humanos de las víctimas ni de los emigrantes ilegales, crear instrumentos que protejan los derechos humanos y tomar medidas para la construcción de la confianza mutua a todo nivel, desde lo diplomático hasta el acercamiento de los diferentes organismos de seguridad.

Aunado a lo anterior, el panorama actual de una buena parte de la sociedad colombiana, los llamados desplazados forzosos, eleva el grado de vulnerabilidad y el riesgo de ser víctimas de la trata de personas. Una de las causas principales del desplazamiento es la presencia de grupos armados al margen de la ley tanto en el campo como en la ciudad que con el ejercicio de la fuerza producen temor a la población civil y por ende, ocasiona una migración masiva. Este grave problema puede alterar y, en efecto, altera el orden público. La razón de ello y de que los desplazados constituyan una población altamente vulnerable, es porque generalmente su migración se da del sector rural al urbano, lo que genera una experiencia bastante traumática para ellos, por las condiciones económicas precarias que deben enfrentar, por el desarraigo familiar, cultural y social y por las pocas oportunidades de conseguir empleo ${ }^{12}$.

En Colombia, igual que a nivel internacional, ocurre que la población receptora de los desplazados no tiene infraestructura suficiente para albergar adecuadamente a los recién llegados, lo cual ocasiona que aumenten los índices de pobreza, inseguridad y otros factores negativos en las principales ciudades del país. Además, "no existe una política estatal que tenga en consideración la asistencia a la población receptora, generando conflictos con el grupo recién llegado y agravando los problemas socioeconómicos propios de la zona"13. Ello aumenta el riesgo de ser víctimas del tráfico de personas. La sentencia T-025 de $2004^{14}$ proferida por La Corte Constitucional habla de 3 millones de población desplazada en el país. Cabe anotar que Colombia es el país que más recibe protección o ayuda del ACNUR para los desplazados internos ${ }^{15}$.

Como se ha indicado, nuestro país es uno de los más afectados por el delito de trata de personas, pues su territorio es origen de muchas de las víctimas, no sólo para comercio sexual, sino para el tráfico de menores y otros. Es considerado como el tercer país exportador de mujeres víctimas de la trata. ${ }^{16}$ Por lo tanto, si se quiere atacar el problema, es prioritario que el

12 Se llega a esta conclusión con base en las encuestas en profundidad hechas a personas en situación de desplazamiento en Aguablanca, Cali-Colombia. Publicadas por la Fundación Esperanza.

13 FUNDACIÓN ESPERANZA, Trata de Personas y Desplazamiento forzado. Estudio exploratorio sobre la vulnerabilidad de la trata de personas en poblaciones en situación de desplazamiento en Aguablanca, Cali-Colombia. Memo O. y Cia Ltda. Cali - Colombia. 2004. p. 18.

14 En esta sentencia la Corte Constitucional exige al gobierno atender los tres millones de desplazados que se estima hay en el país.

15 Las cifras de desplazados internos en Colombia ha aumentado 1.2 a 2 millones, según el informe ACNUR 2005.

16 ORGANIZACIÓN INTERNACIONAL PARA LAS MIGRACIONES. La Trata de Personas es la Esclavitud Moderna. Campaña Nacional Contra la Trata de Personas. Bogotá. 2004. p. 4. 
Estado colombiano adopte medidas socioeconómicas de fondo para enfrentar los problemas de pobreza, educación y desarrollo, y de esta forma prevenir y combatir el tráfico ilícito de migrantes colombianos. Aunque se han dado algunos pasos importantes en esta dirección, son insuficientes para garantizar que haya un desarrollo social incluyente que llegue por igual a todos los grupos poblacionales y a todas las regiones, en especial aquellas áreas rurales que requieren un esfuerzo especial por parte del Estado. En ese sentido, agrava la situación la desigualdad en la distribución del ingreso entre las zonas rurales y urbanas por el poco acceso a los servicios de educación y salud, así como la falta de oportunidad de empleo con una remuneración justa, todo lo cual aumenta las posibilidades para los traficantes de personas. Sin embargo, "Los cambios necesarios no pueden ser abordados por organizaciones aisladas ni por proyectos puntuales, sino que deberán establecerse fórmulas sistemáticas y persistentes de interacción social"17 que promuevan, mejoren y garanticen el acceso a salud, educación, vivienda a las personas más vulnerables de ser tratadas.

\section{ÁMBITO LEGAL}

Una tarea de vital importancia para la erradicación del delito de trata de personas en el contexto colombiano es ajustar el sistema de justicia y buscar una integración jurídica a nivel global para combatir efectivamente el flagelo de la trata de personas, que "suele ir acompañado de enormes movimientos de dinero no declarado, de tráfico de drogas y de armas", ${ }^{18}$ porque en la mayoría de los casos los tratantes no son descubiertos, lo que dificulta el sometimiento de éstos a la ley. Entre las causas se encuentran las pocas denuncias que se presentan por parte de las victimas por miedo a represalias de las bandas de tratantes; aunque, como se indicó antes, éstas han aumentado en un 34\% con relación a años anteriores según la Fiscalía General de la Nación y las estadísticas del Departamento Administrativo de Seguridad (D.A.S). Así mismo, las investigaciones, enjuiciamiento y condenas en el 2006 aumentaron considerablemente en relación con el 2005 así: se abrieron 49 investigaciones, 75 enjuiciamientos que doblan el número del año anterior y diez (10) condenas que corresponde a un incremento de cinco (5) veces desde el 2005, según Informe Anual Sobre Trata de Personas, 2007. Departamento de Estado, Oficina de Vigilancia y Lucha contra la Trata de Personas.

Sin embargo, una de las dificultades que se presentan en la lucha contra la trata es que en la mayoría de los tratados internacionales y propuestas de la sociedad civil hay una tendencia marcada a centrar su preocupación en las víctimas, con poco énfasis en el castigo de los tratantes. De ahí, que "un excesivo énfasis en la víctima puede dejar de lado lo que debe ser la

\footnotetext{
17 GALLICCHIO, Enrique. El desarrollo local en América Latina, Estrategia Política basada en la Construcción de Capital Social. Córdoba, Argentina. Mayo. 2004. p. 18.

18 Fernando Díaz identifica los delitos conexos de la trata de personas.
} 
preocupación fundamental de la justicia, que es la investigación y sanción de los promotores y gestores del crimen, en este caso, los traficantes"19. Lo que representa, "una salida fácil y cómoda para evitar la tarea más difícil, comprometida y austera, es decir, el combate a los responsables de estos crímenes" ${ }^{\prime 20}$.

A pesar de ello, Colombia es considerada como uno de los países más avanzados en el combate de este delito, por cumplir los estándares mínimos para la eliminación de la trata de personas, según el TIP Report de 2005. ${ }^{21}$ Dentro de las estrategias para la lucha del tráfico de personas está la firma y ratificación de instrumentos internacionales, como la Convención de las Naciones Unidas contra el Crimen Organizado Transnacional y sus protocolos complementarios, entre ellos el Protocolo para Prevenir, Reprimir y Sancionar la Trata de Personas especialmente de Mujeres y Niños ${ }^{22}$. También ha promulgado leyes de carácter nacional, como la Ley 985 de 2005, que tiene por objeto adoptar medidas de prevención, protección y asistencia necesarias para garantizar el respeto de los derechos humanos de las víctimas y posibles víctimas de la trata de personas, tanto las residentes o trasladadas en el territorio nacional, como los colombianos en el exterior, y para fortalecer la acción del Estado frente a este delito. Esta ley es un avance significativo en la legislación nacional porque involucra medidas de prevención, protección y asistencia a las víctimas, tales como la de investigar y procesar a quienes cometan el delito de trata de personas. Por consiguiente, apuntar a un equilibrio entre persecución y sanción a los traficantes y prevención y protección a las víctimas, es ideal para lograr resultados, ya que significa atacar tanto la oferta como la demanda ${ }^{23}$.

No obstante, estas estrategias podrán adquirir mayores cobertura y fortaleza en la medida que los múltiples acuerdos se articulen e incorporen a las legislaciones nacionales en los Estados, tanto de origen, tránsito y destino. Esa articulación contribuirá a conformar una apertura legal,

19 CHIAROTTI, Susana. La Trata de Mujeres: Sus Conexiones y Desconexiones con la Migración y los Derechos Humanos. Naciones Unidas-CEPAL. Serie Población y Desarrollo. \# 39. mayo, 2003. p. 21.

20 Ibid., p. 24.

21 La ley de los Estados Unidos exige que el Departamento de Estado presente un informe anual al Congreso sobre los esfuerzos que han hecho los gobiernos extranjeros para eliminar las formas graves de la trata de personas y a partir de ahí, clasificarlos según Trafficking Victims Protection Act-Minimum Standards for the Elimination of Trafficking in Persons (TVPAs). En el último informe del Departamento de Estado de los Estados Unidos sobre trata de personas de 2005 (trafficking in persons report, june 2005) Colombia está clasificada en la categoría uno (1). La escala es de 1 a 3. siendo uno (1) los que hacen significativos esfuerzos y cumplen los mínimos requisitos para combatir el tráfico de personas. La categoría dos (2) los que hacen esfuerzos para cumplir los estándares mínimos y tres (3) aquellos gobiernos que no cumplen con los estándares mínimos y no hacen esfuerzos significativos para hacerlo. A pesar de encontrarse Colombia en la categoría uno (1), el informe insta al Estado colombiano a hacer mayores esfuerzos como a agilizar los procesos y mejorar el monitoreo de casos de trata de personas., porque en 2004 no hubo condenas. Aunque reconoce la captura y extradición de un traficante español y la investigación de veinte (20) nuevos casos. Fuente: bogota.uembassy.gov. actualizada junio7de 2006.

22 Colombia lo firmó el 12/12/2000 y lo ratificó mediante la Ley 800 del 13 de marzo de 2003.

23 EVERTS, Daan. The Brown Journal of World Affairs. Vol. 10. Summer/Fall. 2003. Citado por: Andrea M. Bertone. Transnational Activism to Combat Trafficking in Persons. College Park Scholars International Studies. p. 9. (traducción libre). 
sustentando y fortaleciendo las leyes locales para la investigación y posterior juzgamiento de los culpables de la trata de personas.

La misma ley tiene como propósito impedir que se vulneren los derechos humanos, pero cuando las víctimas están fuera del territorio nacional éstos no pueden ser garantizados porque muchas veces los Estados aplican las leyes de inmigración a las víctimas, lo que dificulta su identidad como sujeto pasivo del delito. En algunos casos las víctimas son acusadas de ser inmigrantes ilegales. Al respecto, se produjo una declaración en el Foro de las Américas por la Diversidad y la Pluralidad, en el año 2001, que señala que "ningún ser humano es minoría, ningún ser humano es indocumentado, ningún ser humano es ilegal"24.

A pesar de ello, lo anterior tiende a quedarse en retórica, ya que en los últimos años se han incrementado los controles fronterizos entre los países. Igualmente, han aumentado la xenofobia, el racismo y otros tipos de discriminación. Por ejemplo, a raíz de los nefastos hechos del 11 de septiembre de 2001, en los que fueron destruidas las Torres Gemelas en Nueva York y parte del pentágono en Washington, Estados Unidos fortaleció los controles fronterizos y promulgó La Doctrina Preventiva, bajo la cual cualquier persona puede equivocadamente ser catalogada como terrorista y ser tratada como tal, en desarrollo del nuevo mandato de combate a cualquier forma de terrorismo. En el contexto europeo, concretamente en el Reino Unido, se puede señalar la nueva legislación de Seguridad, Crimen y Lucha contra el Terrorismo, que autoriza la detención indefinida de los sospechosos de terrorismo de nacionalidad extranjera.

Además, con base en la Doctrina Preventiva por la necesidad de mantener al mundo libre de cualquier amenaza de terrorismo, se legitiman acciones que violan los derechos humanos y la dignidad de la persona. Como dijo Norman Birnbaum ${ }^{25}$, hay un vocerío planetario contra el terrorismo ${ }^{26}$. Entonces, la garantía a los derechos humanos de las victimas del delito de trata de personas está supeditada a las leyes de inmigración de los diferentes Estados y no a una normativa universal, lo que hace más vulnerables a quienes padecen este delito.

En tal caso, la verdadera garantía a los derechos humanos se manifiesta en la oportunidad de las víctimas de recuperarse de su situación y asegurar que los tratantes sean procesados. También se requiere que en el país receptor, las personas sospechosas de ser víctimas del tráfico humano, tengan acceso a asistencia médica, legal, psicológica y material. Igualmente, es necesario que los Estados se comprometan a otorgar alojamiento y protección a las vícti-

CHIAROTTI, Op. cit., p. 20.

25 Catedrático en la Universidad de Georgetown, autor de varias obras. Su último libro: American Social Reform And European Socialism in the Twentieth Century.

26 BIRNBAUM, Norman. Después del 11 de Septiembre. Fundación Marcelino Botín. Madrid-España. 2003. p. 101. 
mas, así como a asegurarles que la policía local los protegerá de represalias por parte de las organizaciones criminales que los trataron. En caso de que la decisión sea repatriarlos, deben cerciorarse que no sufran discriminación, estigmatización o sean nuevamente perseguidos, convirtiéndose una vez más en blanco de las organizaciones criminales.

Si bien es cierto que lo anterior resulta determinante en el combate del delito de la trata de personas, también es indispensable la disposición que muestran los Estados para alcanzar logros significativos, porque la voluntad por sí sola es insuficiente. Entonces, el factor decisivo por la magnitud, complejidad y alcance del delito, sigue siendo el trabajo conjunto tanto del sector público como privado. En este último grupo, la participación de la sociedad civil es definitiva para el logro de las metas propuestas con miras a derrotar o por lo menos a disminuir el impacto de esta agresión de gran magnitud y de consecuencias catastróficas para las personas victimas de las bandas de tratantes. A pesar de, para conseguir involucrar a los gobiernos, a la sociedad civil y a la comunidad internacional, debe haber una gran sensibilización del problema que se traduzca en poder conocerlo y reconocerlo, para así hacer recomendaciones y prescribir acciones encaminadas a minimizar los efectos drásticos del delito y apuntar a la supresión de este flagelo.

\section{CONCLUSIÓN}

La trata de personas es una violación a los derechos humanos que requiere una especial atención por parte del Estado. Colombia ha mostrado voluntad para combatir eficazmente el delito al suscribir tratados internacionales, promulgar y sancionar leyes nacionales. Sin embargo, estas medidas son insuficientes. Sólo con unas reformas socioeconómicas justas se puede garantizar a la mayoría de la población un desarrollo sostenible que disminuya la brecha entre ricos y pobres, agravada por el fenómeno de la globalización que incide en el aumento del delito transnacional y su modalidad de tráfico ilegal de personas. Así mismo, a través de acciones conjuntas entre los diferentes gobiernos de los países de origen, tránsito y destino y demás actores de la sociedad internacional, se puede lograr disminuir significativamente la trata de personas, no sólo en Colombia sino en el mundo. Esto, conlleva a pensar seriamente en la cooperación internacional como una herramienta eficaz para el combate de la trata de personas y ésta a su vez virar hacia las organizaciones no gubernamentales con infraestructura instalada y experiencia en este campo.

Otra tarea de vital importancia para la erradicación de este delito en el contexto colombiano es ajustar el sistema de justicia. En la mayoría de los casos los tratantes no son descubiertos, lo que dificulta el sometimiento de éstos a la ley. En esta labor deben estar comprometidos todos los estamentos de la sociedad para conseguir una diplomacia consensuada que aborde este problema en toda su complejidad. Por lo tanto, es decisivo el trabajo conjunto tanto del sector público como del sector privado. 
Para este propósito, una de las gestiones más importantes del trabajo conjunto es la promoción del respeto a los derechos humanos, que garantice principios como la libertad y la dignidad humana. Entonces, los hacedores de política, organizaciones públicas y privadas del ámbito nacional, deberán asumir nuevas responsabilidades frente a los desafíos que presenta el combate de la trata de personas para el Estado colombiano, en correspondencia con una estrategia común que privilegie los derechos humanos.

\section{BIBLIOGRAFÍA}

AHUMADA, Consuelo. El Modelo Neoliberal y su impacto en la sociedad colombiana. El Áncora Editores. Bogotá. 1998.

ARDILA, Martha. Los Nuevos Flujos Poblacionales y la Política Exterior Colombiana. Colombia y su Política Exterior en el siglo XXI. FESCOL. Bogotá.

BERTONE. Andrea M. Transnational Activism to Combat Trafficking in Persons.College Park Scholars International Studies.

BIRNBAUM, Norman. Después del 11 de Septiembre. Fundación Marcelino Botín. Madrid-España. 2003.

CHIAROTTI, Susana. La Trata de Mujeres: Sus Conexiones y Desconexiones con la Migración y los Derechos Humanos. Naciones Unidas-CEPAL. Serie Población y Desarrollo. \# 39. mayo, 2003.

EVERTS, Daan. The Brown Journal of World Affairs. Vol. 10. Summer/Fall. 2003. Citado por: Andrea M. Bertone. Transnational Activism to Combat Trafficking in Persons. College Park Scholars International Studies (traducción libre).

Fiscalía General de la Nación y la Estadística del DAS.

FUNDACIÓN ESPERANZA, Trata de Personas y Desplazamiento forzado. Estudio exploratorio sobre la vulnerabilidad de la trata de personas en poblaciones en situación de desplazamiento en Aguablanca, Cali-Colombia. Memo O. y Cia LTDA. Cali - Colombia. 2004.

GALLICCHIO, Enrique. El desarrollo local en América Latina, Estrategia Política basada en la Construcción de Capital Social. Córdoba, Argentina. Mayo. 2004.

Informe ACNUR 2005.

MEMORIAS, Encuentro Internacional: La Aplicación de la Justicia en la Trata de Personas. Intercambio de Experiencias. Bogotá - Colombia. Marzo 2005. 
ORGANIZACIÓN INTERNACIONAL PARA LAS MIGRACIONES. La Trata de Personas es la Esclavitud Moderna. Campaña Nacional Contra la Trata de Personas. Bogotá. 2004.

PROGRAMA DE LAS NACIONES UNIDAS PARA EL DESARROLLO. Informe Nacional de Desarrollo Humano Colombia - 2003.

U.S. Department of State. 2005 Report. Victims of Trafficking and Violence Protection Act of 2000: Trafficking in Persons Report. http://www.state.gov/g/tip/rls/tiprpt/2005/ bogota.uembassy.gov 